\title{
Jane Lancaster and Human Nature
}

\section{An Evolutionary Anthropology Pioneer}

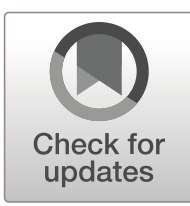

\author{
Robert K. Hitchcock ${ }^{1}$
}

Published online: 23 May 2020

(C) Springer Science+Business Media, LLC, part of Springer Nature 2020

When Jane Lancaster arrived in Albuquerque as a new professor in the Department of Anthropology at the University of New Mexico in the fall of 1985, she felt like she was coming home. As a child, she spent a lot of time in New Mexico, and she had relatives in the state. She quickly made her mark in the UNM Anthropology Department, helping to set up an evolutionary anthropology program, one of the first of its kind in the world.

Jane Lancaster's work is groundbreaking and trendsetting in a number of disciplines. In primate studies she worked on the similarities and differences between humans and nonhuman primates (see Lancaster 1975). Other areas include play and parenting, human mating and family formation strategies, and the evolutionary biology of women. Her work is intriguing not only because of its high scientific quality but also because of the breadth of areas that she has covered.

As a UNM Distinguished Professor, Jane Lancaster is without a doubt one of the most prominent anthropologists and human evolutionary scientists living today. One of the pioneering female anthropologists who ushered in a new era of women's scholarship in anthropology, Jane wrote a series of landmark publications on the female life course, parental investment, the division of labor, parenting strategies, pregnancy, women's and men's sexual behavior, life history theory, and the demographic correlates of paternity.

Dr. Lancaster has made significant contributions in research areas ranging from human biology and primatology to sociology and psychiatry. She is considered internationally to be one of the finest theoreticians of her time, and she is seen as highly sophisticated in the various methods that she employs. She is well aware of the need to look at the ways in which opportunities and threats vary according to gender, age, identity, income levels, and proximity to or distance from infrastructure and towns, among other variables. Her research experience, her observational abilities, and her well-balanced theoretical and methodological expertise have given her a nuanced view of the implications of change in the life course for both primates and humans. These are highly significant areas of research, and her desire and ability to obtain emic (actororiented) and etic (behavioral) data and perspectives is laudatory.

Robert K. Hitchcock

RKHitchcock@gmail.com

1 Department of Anthropology, University of New Mexico, Albuquerque, NM 87131, USA 
From her graduate school days at the University of California-Berkeley, Jane has published groundbreaking articles and books and has done studies that have set international trends. She has had impacts on nearly all of the subfields of anthropology, and she has been a major force in the study of human evolution, parenting, primate play, biosocial approaches to sexuality, and socialization. Her work with Kermyt Anderson, Hillard Kaplan, and others on the Albuquerque Men's study not only had implications for our understanding of sexual behavior of males but also helped explain some of the patterning seen in HIV/AIDS transmission and prevention. Lessons learned in Albuquerque have been applied around the world, especially in southern Africa, the global epicenter of the AIDS pandemic.

She has obtained substantial research funding for her work and has been part of major research teams that have received large grants from numerous agencies, ranging from the U.S. National Science Foundation and the Harry Frank Guggenheim Foundation to the William T. Grant Foundation and the National Institute of Child Health and Human Development. In terms of national service, she has been a member or chair of committees in the Social Science Research Council, the American Association for the Advancement of Science, the American Anthropological Association, the Carnegie Council on Adolescent Development, the William T. Grant Foundation Faculty Scholars Program, and the Human Behavior and Evolution Society. Much of her personal time in Albuquerque has been devoted to support for the work of the Albuquerque Chapter of the National Alliance on Mental Illness (NAMI).

As Jane herself told me, "I never would have gotten all the breaks and support from the Social Science Research Council (such as a conference series and the journal) if Mel Konner and I (both student proteges of Sherwood Washburn and Irven DeVore) had not presented ourselves as a fresh alternative to all of the struggles between ethnology and sociobiology." A crucial outgrowth of the work with the Social Science Research Council was the founding of Human Nature, now one of the premier interdisciplinary journals in anthropology and human evolutionary studies (Lancaster 1990). Many of her students at Oklahoma and New Mexico have gone on to make substantial contributions of their own, some examples including Barbara King (College of William and Mary), Sara E. Johnson (California State University, Fullerton), Sharon

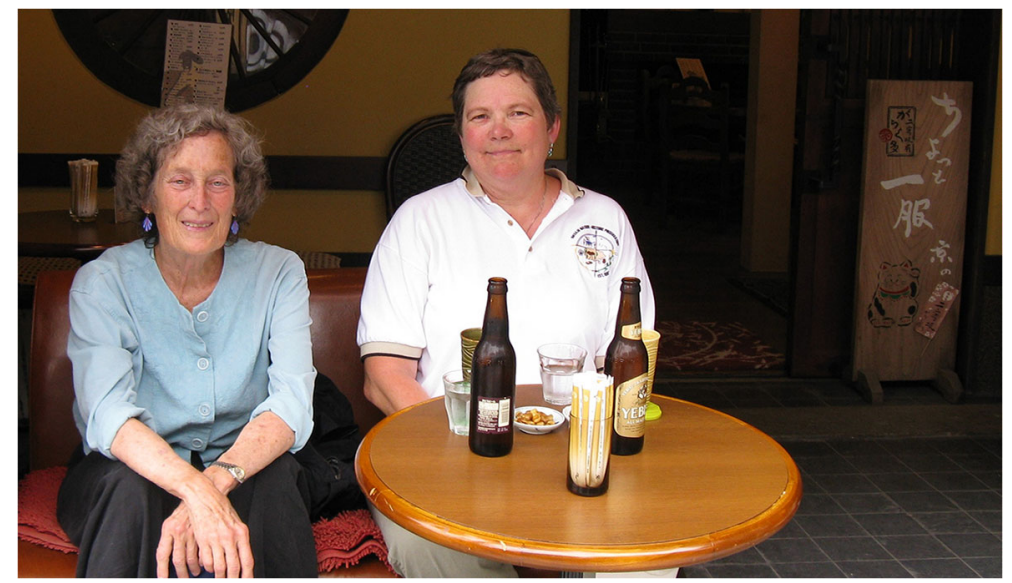

Fig. 1 Jane and June-el after a hot and humid afternoon of sightseeing at the 2008 Human Behavior and Evolution Society conference, Kyoto, Japan 
Pochron (Stony Brook University), Lisa Rapaport (Clemson University), Elizabeth Eadie (University of Arizona), and Louis Calistro Alvarado (University of Pittsburgh), the last of whom is now the editor of Human Nature. (See Alvarado 2020 for his inaugural editorial.)

As an editor, Jane did not shy away from controversial subjects, one example being the debates over the work of Napoleon Chagnon and James Neel among the Yanomamo, which was called into question by a journalist, Patrick Tierney, in his 2001 book Darkness in El Dorado. The paper that she wrote with Raymond Hames (Lancaster and Hames 2011) to introduce Alice Dreger's assessment of the controversy is one of the more influential papers in social and evolutionary science today. Jane, with the able assistance of June-el Piper, not only made editorial decisions for Human Nature but also provided prospective authors with enormous help framing their arguments, ensuring that they addressed relevant literature, and coming up with innovative ideas (Fig. 1).

From a personal perspective, Jane is empathetic, well-rounded, imaginative, extremely hard-working, and deeply committed to ensuring that her research has practical as well as academic significance. She has managed to keep a superb balance between her work as a teacher and mentor and her personal life, which has been heavily committed to her sons, to her many friends and colleagues, and to the public at large.

\section{References}

Alvarado, L. C. (2020). A legacy of interdisciplinary biosocial science, with more work to be done. Human Nature, 31(2). https://doi.org/10.1007/s12110-020-09366-5.

Lancaster, J. B. (1975). Primate behavior and the emergence of human culture. New York: Holt, Rinehart \& Winston.

Lancaster, J. B. (1990). An interdisciplinary, biosocial perspective on human nature. Human Nature, 1, 1-2. Lancaster, J. B., and R. B. Hames. (2011). Statement on the publication of Alice Dreger's investigation, "Darkness's descent on the American Anthropological Association: A cautionary tale." Human Nature, $22,222-223$.

Publisher's Note Springer Nature remains neutral with regard to jurisdictional claims in published maps and institutional affiliations. 